\title{
Urgences
}

\section{Lettre à Stéphane}

\section{Jean-Pierre Vidal}

Numéro 15, octobre 1986

Épigraphiques

URI : https://id.erudit.org/iderudit/025335ar

DOI : https://doi.org/10.7202/025335ar

Aller au sommaire du numéro

Éditeur(s)

Urgences

ISSN

0226-9554 (imprimé)

1927-3924 (numérique)

Découvrir la revue

Citer ce document

Vidal, J.-P. (1986). Lettre à Stéphane. Urgences, (15), 73-74.

https://doi.org/10.7202/025335ar

Ce document est protégé par la loi sur le droit d'auteur. L'utilisation des services d'Érudit (y compris la reproduction) est assujettie à sa politique d'utilisation que vous pouvez consulter en ligne.

https://apropos.erudit.org/fr/usagers/politique-dutilisation/
Cet article est diffusé et préservé par Érudit.

Érudit est un consortium interuniversitaire sans but lucratif composé de l’Université de Montréal, l'Université Laval et l'Université du Québec à Montréal. Il a pour mission la promotion et la valorisation de la recherche. https://www.erudit.org/fr/ 


\section{Jean-Pierre Vidal LETTRE Â STÉPHANE}

Alchimiste des riens qui le faisaient surviure.

Robert Pinget: Passacaille

Une fois précipitée l'épiphanie, nié, pour fonder, l'être, ne reste que ça. Oũ nul rebours - s'entend, s'il fût possible, vers le noroît de l'exergue souverain - ne venant faire aversigne, chute ici de l'inculte d'alors, pas d'autre recours qu'un précipice d'infime lent en forme de fiction sans doute, née de quoi.

À cinq heures donc, comme le temps fraîchissait, on a déployé la marquise de l'hôtel et je suis descendu au bar. Déjà gris, le pianiste, nonchalance délibérée, risquait quelques mesures de "Misti". Le brouillard s'étire comme un chat. Délivré de ce rien qui me pliait, c'est selon, l'âme ou les reins, j'écris dans ce carnet: "pas lu Polders". Quoique.

Ou quelque détour, butant probablement sur la trace de son vieux parcours, coude obligé de tout cité, en pluie s'inverse. Ce sont stries hors la cible.

En cinquante ans, et j'en ajoute, de vie quiète et feutrée, il avait assemblé une collection d'images, articulées d'un commentaire tu, leur succession ce temps du calcul de la chair, rides du désir, ironie effeuille. Un imperceptible mouvement du membre ou torsion autre de la bouche vers quoi et son plaisir, dans la succession avérée, conquise, par une aléatoire parce qu'involontaire recherche, s'exacerbait cri. Marais du moite sur feuille de lumière, éclat parfois, tournée bouclée, d'autre rien.

Mais le nom toujours clôt qui nie sombre. Ici, lyrisme hélas. Or, la mécanique ne fera toujours jamais foi que du toucher encore. Où fuir lors? Excepté peut-être enfin bâcler. Sursis de lignes. En vue de quelle.

Tel imperceptible grain, de beauté dit, n'aurait pu tout au plus lui donner que raison, mais le décor déjà, de plus. Seul l'infini dérisoire dirait la collecte éteinte. Et puis sans doute une autre, peau entr'aperçue, à offrir à sa gourmande quête, un projet d'épinglage adverse. II paraît qu'il faut vivre.

Surenchère inutile, l'écriture à rien plus désormais ne rime. 
Blanc vers.

Comme impassiblement mué, mains ricochets trilles, le piano se propose Monk, je refermerai l'album qui excède ce carnet et sur un dernier hoquet fellatoire là, sans nul doute on démontrera. 